\title{
Emotionalization in Science
} Communication: The Impact of Narratives and Visual Representations on Knowledge Gain
and Risk Perception

\author{
Danny Flemming ${ }^{1}$, Ulrike Cress ${ }^{1,2}$, Sophia Kimmig ${ }^{3,4}$, Miriam Brandt ${ }^{3}$ and \\ Joachim Kimmerle ${ }^{1,2 *}$
}

${ }^{1}$ Leibniz-Institut für Wissensmedien, Knowledge Media Research Center, Tübingen, Germany, ${ }^{2}$ University of Tübingen, Tübingen, Germany, ${ }^{3}$ Leibniz Institute for Zoo and Wildlife Research, Berlin, Germany, ${ }^{4}$ Freie Universität, Berlin, Germany

\section{OPEN ACCESS}

Edited by: Andrea M. Feldpausch-Parker, State University of New York College of Environmental Science and Forestry, United States

Reviewed by: Richard Buttny, Syracuse University, United States Bridie McGreavy, University of Maine, United States Markus J. Peterson, University of Texas at El Paso, United States

*Correspondence: Joachim Kimmerle j.kimmerle@iwm-tuebingen.de

Specialty section: This article was submitted to Science and Environmental Communication, a section of the journal Frontiers in Communication

Received: 05 October 2017 Accepted: 11 January 2018 Published: 26 January 2018

Citation:

Flemming D, Cress U, Kimmig S, Brandt M and Kimmerle J (2018)

Emotionalization in Science Communication: The Impact of Narratives and Visual Representations on Knowledge Gain and Risk Perception.

Front. Commun. 3:3. doi: 10.3389/fcomm.2018.00003
The communication of scientific information plays an increasingly important role for scientists and scientific institutions. This is especially true of institutions in the field of biodiversity and conservation research, since the transfer of research results to the public is a prerequisite for decision-making, and the success of conservation measures often depends on public acceptance or active contribution. To have the desired impact, science communication in the context of human-wildlife interactions must enable recipients to (1) gain valid knowledge, (2) form an attitude toward the subject matter, and (3) develop an adequate understanding of the risks and dangers associated with human-wildlife interactions, which are usually overestimated by the general public. Using the topic of foxes in urban habitats, we investigated the role of emotionalization in science communication. In a laboratory experiment with 127 university students (91 females), we manipulated textual and visual features in an information brochure about foxes and examined their impact on people's knowledge gain, attitude development, and modified risk perception. In particular, we compared a narrative presentation to a non-narrative list of facts and examined the use of photographs of young foxes. We found a positive development in all of the outcome variables from the pre- to the posttest (more knowledge, more positive attitude, lower risk perception). We also found an interaction effect of text type and visualization on knowledge gain that highlighted the importance of the fit between text type and visualization. In contrast to our expectations, we did not find any differential effects of specific treatments on attitude development. Finally, we found a main effect of text type on modified risk perception, indicating less reduction of risk perception with a narrative article than with a fact list. We discuss our findings with respect to the role of emotionalization in science communication, stressing that it is particularly important to achieve a suitable fit between textual and visual forms of emotionalization, depending on the goal of communication. We also discuss possible explanations as to why some hypotheses were not supported by the data. In our concluding statements, we refer to limitations of the present study and address implications for future research.

Keywords: science communication, emotionalization, narratives, human-wildlife interaction, knowledge, attitude, risk perception 


\section{INTRODUCTION}

In a society where virtually every aspect of our lives is in some way based on science and technology, it is very important for the public to understand the findings and achievements of scientific research (Sapp et al., 2013; Sinatra et al., 2014). In addition, research institutions are subject to increasing scrutiny regarding their use of public funding. Therefore, communicating scientific information to the public has become an increasingly important part of scientific work (Brossard and Scheufele, 2013; Garvey, 2014). Scientists and scientific institutions place more and more emphasis on efforts to make their research results accessible to and usable by relevant stakeholders, policy makers, and society in general (de Bruin and Bostrom, 2013; Garvey, 2014). Many research institutions have, therefore, expanded their knowledge transfer and science communication activities (Brossard, 2013; Brossard and Scheufele, 2013). Reporting relevant information to the public is a crucial issue for institutions in the field of biodiversity research, which aim to contribute to the battle against the current extinction crisis (Decker et al., 2016). Designing appropriate methods for conservation requires the transfer of research results to relevant stakeholders, to provide a scientific basis for decision-making and developing solutions (Enck et al., 2006). Research results also need to be transferred to the general public in order to create acceptance for resulting actions (Cook et al., 2013). Without a scientific basis and the support of the public, conservation programs in most cases will not be as effective as they could be (Meijaard and Sheil, 2007). Pertinent examples are human-wildlife interactions, where the success of any mitigation measures completely hinges on the cooperation of the people affected. In such cases, it is crucial to implement successful communication to improve public perception of conservation programs and to foster people's tolerance toward wildlife (Bruskotter et al., 2015).

In the context of human-wildlife interactions, successful communication to the public implies that the recipients gain valid knowledge, show a positive development of their attitude, and have an adequate understanding of risks and dangers associated with these interactions (Burns et al., 2003). In order for this knowledge transfer to be effective, scientific results need to be presented in a manner that is comprehensible to the public (Flemming et al., 2015) and that adequately facilitates the three factors mentioned above. However, not much is known as yet about the effects of different forms of representing scientific information. With regard to this issue, science communication and conservation sciences alike can benefit from approaches from the field of psychology (Saunders et al., 2006). Transferring knowledge, supporting attitude formation, and enabling people to assess risk are key tasks of science communication in general and major factors in the public understanding of scientific information (Morgan, 2002; Jacobson et al., 2004; Kimmerle and Cress, 2013; Lundgren and McMakin, 2013; Irwin, 2014; Kimmerle et al., 2015; Feinkohl et al., 2016; Flemming et al., 2017).

An aspect that plays a major role in communication is emotionalization of the information (Höijer, 2010; Kimmerle et al., 2014; Ryffel et al., 2014). Authors in science communication can present the information they strive to communicate in a way that aims to evoke emotional reactions within their readers, in order to encourage them to engage with the respective issue and to foster information processing (Baumeister et al., 2007; Myers et al., 2012). To do so, this intentional evoking of emotions, that is, emotionalization, can be accomplished by different means. One method is through textual features: Storytelling as an instrument for emotionalization is increasingly being practiced in science communication (Nisbet and Scheufele, 2009; Dahlstrom, 2014). This narrative approach may include messages such as testimonials, eyewitness reports, or case studies. Narratives may be particularly appropriate for communicating scientific information to non-experts (Green, 2006; Dahlstrom, 2014). Emotionalization can also be accomplished through visual features. Dealing with human-wildlife interactions lends itself well to this approach, in particular, through pictures of young animals for purposes of positive emotionalization (Nummenmaa et al., 2006; Höijer, 2010). Emotionalization is not only relevant for knowledge transfer but also particularly important for attitude formation (Kim and Morris, 2007; Ryffel et al., 2014) and risk communication (Keller et al., 2006; Slovic and Peters, 2006; Turner, 2007). However, to date, there has not been much experimental work about how the style of information presentation influences people's knowledge acquisition, attitude formation, and perception of the risks of human-wildlife interactions. Most of the existing research is merely qualitative or conceptual work (e.g., Dunlop et al., 2008; for a review, see Petty et al., 2001). Accordingly, the study presented here aims to examine through an experimental approach the impact of emotionalization of narratives and pictures on laypeople's knowledge gain, attitude development, and modification of their perception of the risks of human-wildlife interactions. Our assumption was that people's knowledge, their attitudes, and their risk perception would be influenced by particular textual and visual presentations of scientific information that create emotions in the recipients.

As a prototypical topic for studying how different formats of presenting scientific information to people influence knowledge, attitude, and risk perception, we chose the field of human-wildlife interactions, specifically the human-carnivore relationship. The complex relationship between humans and carnivores has been evident for millennia and has ranged from conflict to mutual benefit (Thornton and Quinn, 2009; Hudenko et al., 2010). The red fox (Vulpes vulpes) has a long history of interaction with humans and has been viewed as a predator of farm animals and as a carrier of infectious diseases such as rabies (Freuling et al., 2013) or alveolar echinococcosis (Fischer et al., 2005; Lewis et al., 2014). The incidence of human-fox interactions has increased with human land development, the process of urbanization, and the expansion of human population and farming frontiers. The active colonization of urban habitats by foxes increases the potential for conflict (Bateman and Fleming, 2012; Śálek et al., 2015). In this situation, science communication is a crucial element in wildlife management and policy. Nevertheless, the social science literature on humans' beliefs, attitudes, and behaviors with respect to carnivores and their management is not very comprehensive (Harrison, 1998; Williams et al., 2002; Hudenko et al., 2010). Our chosen topic is suitable for examining people's knowledge gain, as general knowledge about foxes is limited (Hegglin et al., 
2008). Moreover, many people have a critical attitude and low tolerance toward carnivores near urban habitats (Soto-Shoender and Main, 2013; Kansky et al., 2014). In particular, it appears that people perceive the risks that result from foxes' living in the vicinity of humans to be quite high, specifically the risks of being infected with infectious diseases (König, 2008)—so, this topic is also relevant for studying how particular formats of presentation influence people's risk perception.

The study presented here focused on positive aspects of emotionalization. Regarding the textual features, we compared an information brochure with a positive narrative about foxes to an information brochure with a bare listing of information that contained the exact same facts. Concerning emotionalization through visual features, we also used a positive presentation with photographic pictures of "cute" young foxes. Narratives are supposed to induce interest (Dahlstrom, 2014) and may thus motivate people to keep reading. Narrative texts tend to give examples or provide a continuous story that may foster understanding and deeper processing, which in turn may result in better learning outcomes (Graesser et al., 1980; Kintsch, 1994; Sáenz and Fuchs, 2002; Dunlosky et al., 2013). Narrative texts can also contain additional contextual information, like names or settings, which can serve as clues for information recall (Webb, 2008). Therefore, while people can acquire factual knowledge from any type of text, we assumed that people would acquire more knowledge from a narrative presentation of information than from a pure list of facts. In addition, we assumed that knowledge gain could be influenced by the particular fit between text type and visualization: The message of an emotionalizing article underlined by emotionalizing pictures was considered most likely to support the process of knowledge acquisition, while the fit between a fact list and emotionalizing pictures was not as good.

On the basis of these considerations, we formulated the following hypotheses:

H1: People will acquire additional knowledge between the pre- to the posttest across all conditions.

$\mathrm{H} 2$ : There will be a main effect of text type on knowledge gain, with a higher level of knowledge gain resulting from a narrative article than from a fact list.

H3: There will be an interaction effect of text type and visualization on knowledge gain.

With respect to attitude development we assumed that providing people with information on foxes would have a positive impact on their attitude toward these animals. We also assumed that positive emotionalization through textual as well as through visual representations would have a particularly positive impact on attitude development. Therefore, we formulated these additional hypotheses:

H4: People's attitudes will develop in a positive direction from the pre- to the posttest across all conditions.

H5: There will be a main effect of text type on attitude development, with a more positive development resulting from a narrative article than from a fact list.

H6: There will be a main effect of visualization on attitude development, with a more positive development from presenting positive photographs than using no photographs.
Regarding risk perception, we assumed that people would tend to overestimate the risk of transmissions of infectious diseases and that informing them about the true risk (which is very low) would lower the perception of risk. We also assumed that positive emotionalization would make recipients perceive a lower level of risk inherent in human-wildlife interactions. This assumption applied both to positive emotionalization through a narrative presentation of information and to positive emotionalization thorough photographs. Accordingly, we stated the following hypotheses:

H7: People will modify their risk perception toward a lower level from the pre- to the posttest across all conditions.

H8: There will be a main effect of text type on modified risk perception, with a narrative article resulting in a greater decrease in perception of risk than a fact list.

H9: There will be a main effect of visualization on modified risk perception, with a greater decrease in perception of risk with positive photographs than without photographs.

\section{MATERIALS AND METHODS}

\section{Participants and Design}

In order to warrant a standardized procedure and to allow for precise control of our independent variables, we conducted a laboratory experiment (Berkowitz and Donnerstein, 1982; Levitt and List, 2007). One hundred and twenty-seven university students volunteered to participate in this laboratory experiment and received six Euros for compensation. Ninety-one participants were females, 35 were males, and 1 participant did not indicate her or his sex. Participants' mean age was $M=25.93$ years $(S D=9.32)$. We used text type (narrative article vs. fact list) and visualization (photographs vs. no photographs) as between-subjects factors, resulting in four experimental conditions. The participants were randomly assigned to these conditions, with 31 participants in the narrative article/photographs condition ( 22 females, 9 males), 32 participants in the narrative article/no photographs condition (24 females, 8 males), 32 participants in the fact list/photographs condition (23 females, 9 males), and 32 participants in the fact list/no photographs condition ( 22 females, 9 males, 1 person who did not indicate their gender). The four experimental conditions did not differ in the proportion of males to females.

\section{Procedure}

Participants were recruited via an online participant pool and invited to the laboratory. They were informed in advance that they would receive six Euros for participation in a study that would take $45 \mathrm{~min}$. At the laboratory, they completed the following procedures on computers. First, participants read the instructions and gave written informed consent. Then they took a knowledge test about foxes, answered an attitude questionnaire, and completed a risk perception questionnaire. After that, they were randomly assigned to the four conditions, where they read one of the four information brochures, respectively. Subsequently, they took the same knowledge test again and answered the same attitude and risk perception questions. Then, they were asked to indicate their demographics. The experiment ended with a 
debriefing of the participants, where we explained the purpose of the study to them. Ethical approval was obtained from the Local Ethics Committee of the Leibniz-Institut fuer Wissensmedien (approval number: LEK 2017/001).

\section{Instruments and Material Questionnaires}

The knowledge test that participants had to complete before and after the experimental treatment consisted of nine items. This test aimed to capture the participants' factual knowledge about foxes. The test items consisted of statements about foxes with five statements that were correct and four statements that were wrong. The following item is an example of a correct statement: "Foxes can climb trees." An example of a wrong statement was: "Foxes have no specific mating season, but reproduce year-round." For each statement, the participants had to indicate whether it was true or false. For each item that participants correctly identified as true or false, they received one point.

The attitude questionnaire consisted of four items that participants had to rate on four-point Likert scales (ranging from $0=$ do not agree at all to $3=$ totally agree). A sample item was: "Foxes belong to nature and to the environment of humans and should be allowed to live there." The scores were divided by the number of items, resulting in an attitude score that could range from 0 to 3. Internal consistency (Cronbach's alpha) of this scale was $\alpha=0.67$ in the pretest and $\alpha=0.71$ in the posttest.

The risk perception questionnaire consisted of six items with each item representing an infectious disease. Participants had to estimate for each disease on a four-point Likert scale how they perceived the risk of infection for themselves and for domestic animals (ranging from $0=$ virtually no risk to $3=$ high risk). They also had the opportunity to choose the option "not able to estimate" (this choice was treated as missing data in the analysis and replaced by the mean score of the other choices per participant). The six infectious diseases were rabies, echinococcosis, distemper, foot-and-mouth disease, mange, and morbus metum (note that morbus metum is a non-existing, made-up disease; also, for foot-and-mouth disease the risk of infection is objectively nonexistent). Finally, the scores were divided by the number of items, resulting in a risk perception score that could range from 0 to 3 . Internal consistency (Cronbach's alpha) of this scale was $\alpha=0.79$ in the pretest and $\alpha=0.77$ in the posttest.

\section{Experimental Manipulation}

We used two different text versions, one narrative and one factual list, in order to manipulate text type. Both texts contained the identical factual information. The facts provided in both texts enabled participants to correctly answer all of the items in the knowledge test. In the narrative article, the factual information about foxes was embedded in a newspaper style report about a research project. In this article, a biologist described the everyday life of a couple of foxes called Freddy and Tina that lived in the city and were monitored in the research project. In the fact list, in contrast, the same information was given as a simple listing of statements that provided general facts about foxes. The statements were not connected, but instead were presented as bullet points without any continuous story. For example, one of the statements pointed out: "Foxes are the only dogs that can climb trees." In the narrative article condition, the identical information was provided as follows: "Freddy has formed a habit of climbing trees (when he is in danger), since foxes are the only dogs that can climb." Another example from the fact list was: "Foxes are omnivores (their diet includes rodents, windfall, or food remnants) and have few specific demands on their habitat. This makes them very adaptable." In the narrative article, the same information read: "While foxes in the forest usually feed on rodents and windfall ... Freddy and Tina also plunder a garbage can every now and then to get food remnants. Foxes are absolute omnivores, so they can survive practically everywhere. Freddy usually drags his prey into the den and shares with Tina and the young. Unless he finds a piece of pizza-then he prefers to eat it himself." The narrative article consisted of 841 words; the fact list comprised 307 words.

In order to manipulate visualization, we either accompanied the text by photographs or by no photographs. In the photographs condition, we showed four emotionally appealing pictures of foxes. These pictures were not related to the text with regard to specific content and did not possess any informational value. An example of such a photograph can be seen in Figure 1.

\section{Analysis}

Both of our experimental factors were dichotomous variables, and all of the dependent variables were metric measures. In view of these variable levels, and since we aimed to test both differences hypotheses and interaction hypotheses, we tested our hypotheses by running two-sample $t$ tests (for $\mathrm{H} 1, \mathrm{H} 4$, and $\mathrm{H} 7$ ) and twofactor ANOVAs (for $\mathrm{H} 2, \mathrm{H} 3, \mathrm{H} 5, \mathrm{H} 6, \mathrm{H} 8$, and $\mathrm{H} 9$ ), which are common approaches for analyzing these types of data in general (Aron and Aron, 2002) and in the area of risk communication in particular (e.g., Keller et al., 2006). The significance level was set at $p=0.05$. We provide Cohen's $d$ and partial eta-squared to indicate effect sizes. The following paragraphs depict the results of these analyses that tested each hypothesis.

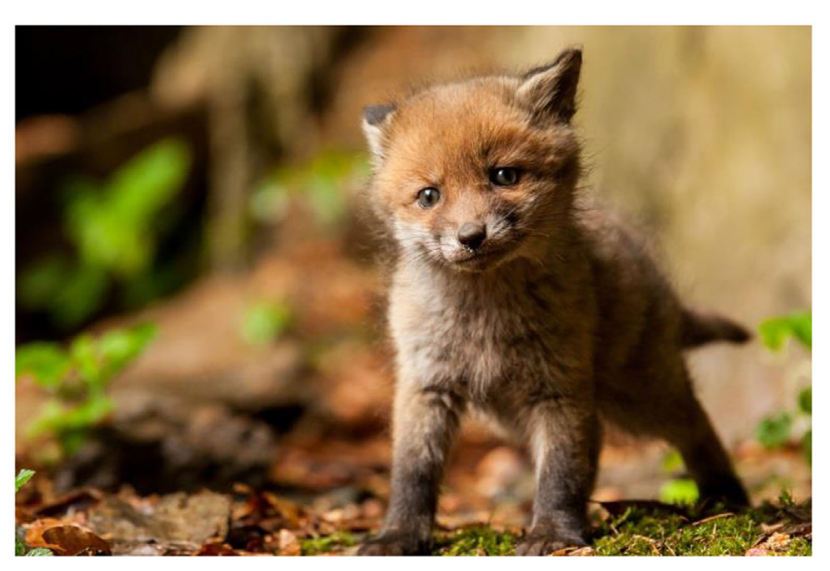

FIGURE 1 | Sample picture of a young fox shown in the photographs condition (this photograph is being reproduced with the permission of the copyright holder, Uwe Schaefer). 


\section{RESULTS}

The results for all $t$ tests and ANOVAs are summarized in Tables $\mathbf{1}$ and 2.

Across all experimental conditions, the participants learnt new facts from the texts they had read. In line with $\mathrm{H} 1$, participants had significantly higher knowledge scores in the posttest $(\mathrm{M}=8.15, \mathrm{SD}=0.92)$ than in the pretest $(\mathrm{M}=5.31, \mathrm{SD}=1.74)$, $t(126)=-17.78, p<0.001, d=1.58$.

In order to capture participants' knowledge gain, we subtracted their knowledge test scores before the manipulation from their scores after the manipulation. This resulted in a knowledge gain score where higher values represented a higher level of knowledge gain. Contrary to the assumption in $\mathrm{H} 2$, we did not find a main effect of text type on knowledge gain, $F(1,126)=1.32$, $p=0.253$.

In line with $\mathrm{H} 3$, we found a significant interaction effect of text type and visualization on knowledge gain, $F(1,126)=13.04$, $p<0.001, \eta_{p}{ }^{2}=0.10$. This effect is shown in Figure 2. Post hoc tests (Bonferroni) indicated that the fact list/photographs condition $(\mathrm{M}=1.94, \mathrm{SD}=1.54)$ differed significantly from the fact list/no photographs condition $(\mathrm{M}=3.41, \mathrm{SD}=1.97), p=0.005$ as well as from the narrative article/photographs condition $(\mathrm{M}=3.39$, $S D=1.31), p=0.006$, but not from the narrative article/no photographs condition $(\mathrm{M}=2.66, \mathrm{SD}=1.94), p=0.578$. The other pairwise comparisons yielded no significant differences.

As expected in $\mathrm{H} 4$, we found that across all experimental conditions the participants had a significantly more positive attitude in the posttest $(\mathrm{M}=2.02, \mathrm{SD}=0.52)$ than in the pretest $(\mathrm{M}=1.87, \mathrm{SD}=0.54), t(126)=-5.55, p<0.001, d=0.49$.

We identified participants' attitude development by subtracting their attitude scores before the treatment from their scores after

TABLE 1 | Pre- and posttest comparisons for knowledge, attitude, and risk perception.

\begin{tabular}{|c|c|c|c|c|c|c|c|}
\hline \multirow[t]{2}{*}{ Outcome variable } & \multicolumn{2}{|l|}{ Pre } & \multicolumn{2}{|l|}{ Post } & \multirow[t]{2}{*}{$t$} & \multirow[t]{2}{*}{$p$} & \multirow[t]{2}{*}{$d$} \\
\hline & $\mathbf{M}$ & SD & $\mathbf{M}$ & SD & & & \\
\hline Knowledge & 5.31 & 1.74 & 8.15 & 0.92 & -17.78 & $<0.001^{\star \star}$ & 1.58 \\
\hline Attitude & 1.87 & 0.54 & 2.02 & 0.52 & -5.55 & $<0.001^{\star *}$ & 0.49 \\
\hline Risk perception & 0.82 & 0.48 & 0.68 & 0.41 & 3.18 & $<0.001^{\star *}$ & 0.28 \\
\hline
\end{tabular}

TABLE 2 | ANOVA results (between conditions) for knowledge gain, attitude development, and modified risk perception.

\begin{tabular}{lllll}
\hline Outcome variable & Predictor & $\boldsymbol{F}$ & $\boldsymbol{p}$ & $\boldsymbol{\eta}_{\boldsymbol{p}}{ }^{2}$ \\
\hline Knowledge gain & Text type & 1.32 & 0.253 & 0.01 \\
& Visualization & 1.47 & 0.228 & 0.01 \\
\multirow{2}{*}{ Attitude development } & Text type $\times$ visualization & 13.04 & $<0.001^{* \star}$ & 0.10 \\
& Text type & 0.64 & 0.424 & 0.00 \\
& Visualization & 0.21 & 0.648 & 0.00 \\
Modified risk perception & Text type $\times$ visualization & 0.06 & 0.810 & 0.00 \\
& Text type & 6.54 & $0.012^{*}$ & 0.05 \\
& Visualization & 3.78 & 0.054 & 0.03 \\
& Text type $\times$ visualization & 0.42 & 0.516 & 0.00 \\
\hline
\end{tabular}

${ }^{*} p<0.05 ;{ }^{* *} p<0.01$ the treatment. Accordingly, positive scores indicated a positive development. Contrary to the assumptions in H5 and H6, we found neither a main effect of text type on attitude development, $F(1,126)=0.64, p=0.424$, nor a main effect of visualization on attitude development, $F(1,126)=0.21, p=0.648$.

As assumed in H7, we found that across all experimental conditions the participants perceived the risk of infection to be lower after reading the texts. The posttest $(\mathrm{M}=0.68, \mathrm{SD}=0.41)$ differed significantly from the pretest $(\mathrm{M}=0.82, \mathrm{SD}=0.48)$, $t(124)=3.18, p=0.001, d=0.28$.

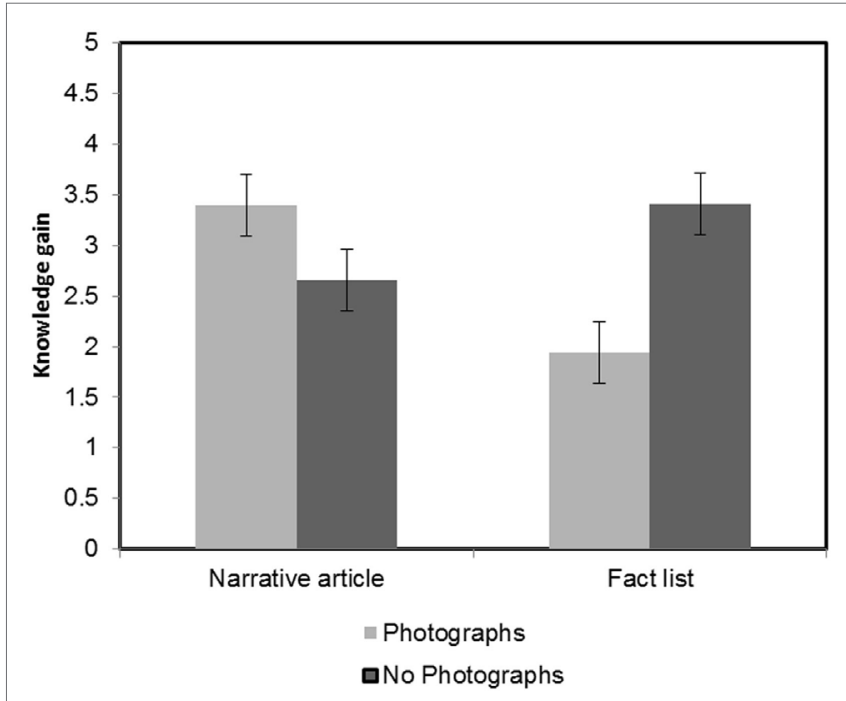

FIGURE 2 | Interaction effect of text type (narrative article vs. fact list) and visualization (photographs vs. no photographs) on knowledge gain as the difference between knowledge posttest and knowledge pretest. Error bars represent SEs.

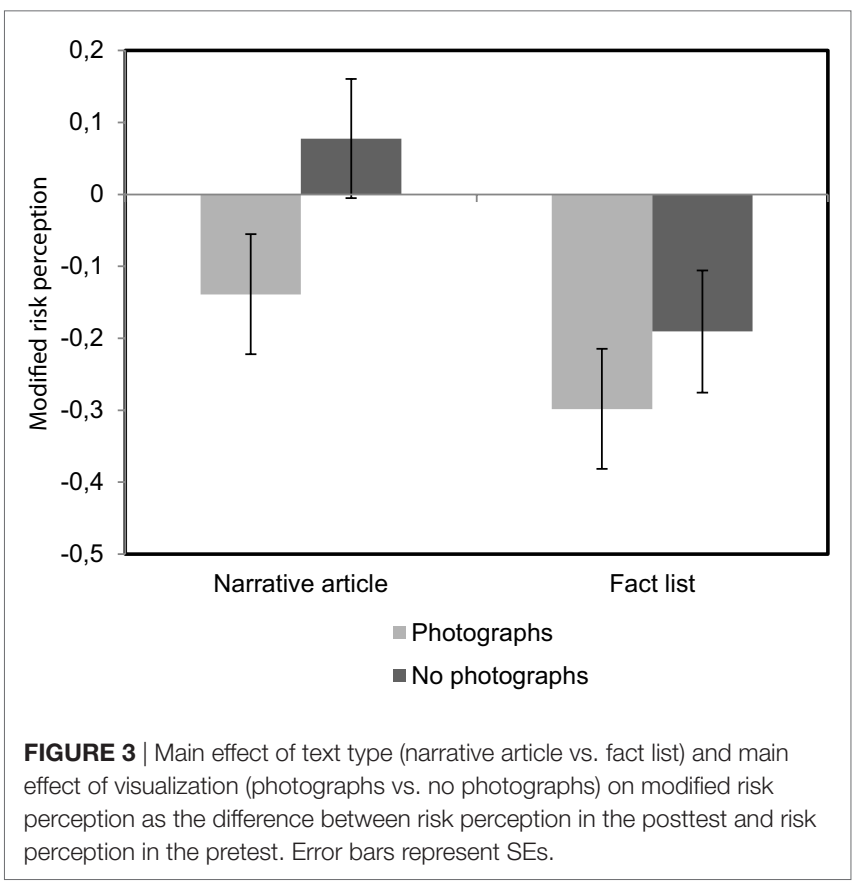


We ascertained participants' modified risk perception by subtracting their risk perception scores before the manipulation from their scores after the manipulation. This resulted in a score where negative values represented a modification of risk perception toward a lower risk of infectious diseases transmitted by foxes. The data also supported $\mathrm{H} 8$ as we found a significant main effect of text type on modified risk perception, $F(1,124)=6.54, p=0.012$, $\eta_{p}{ }^{2}=0.05$. But contrary to our hypothetical assumption, there was a stronger decrease of risk perception with a fact list $(M=-0.25$, $\mathrm{SD}=0.42)$ than with a narrative article $(\mathrm{M}=-0.03, \mathrm{SD}=0.52)$.

Finally, the data did not fully support H9. There was only a marginal main effect of visualization on modified risk perception, $F(1,124)=3.78, p=0.054$. There was a tendency toward a greater decrease of risk perception in the photographs condition $(\mathrm{M}=-0.22, S D=0.51)$ than in the no photographs condition $(\mathrm{M}=-0.05, S D=0.44)$. These effects are illustrated in Figure 3.

\section{DISCUSSION}

In order to preserve biodiversity and deal with human-wildlife interactions, people need to have factual knowledge about the issue at hand and a certain level of tolerance toward wildlife. Therefore, for research institutions in the fields of biodiversity and conservation biology, effective communication of scientific results plays an important role. Science communication has diversified considerably over the last several years, employing an ever-increasing spectrum of formats and instruments. One factor that is increasingly taken into account in this context is emotionalization. There is evidence that emotionalization may have an influence on knowledge, attitude, and risk assessment, three aspects of public opinion that are particularly relevant for science communication and the public understanding of science. The purpose of this study was to test how much of an influence textual and visual features of emotionalization can have on these three aspects. Therefore, we chose the topic of human-wildlife interaction where emotionalization could be examined particularly well, using the example of foxes in urban habitats.

We found that textual emotionalization created by using a narrative did not lead to any higher knowledge gain than a non-emotionalizing fact list, although both text versions substantially improved the participants' knowledge about foxes. In combination with visual emotionalization, however, we found an interaction effect: When accompanied by emotional photographs of foxes, the fact list was less successful in improving readers' knowledge about foxes. We also found that all of our treatments led to a more positive attitude toward foxes in the vicinity of humans. There were no differences in change of attitude between the two text types or the visualization conditions. Additionally, we found decreased risk perception across all conditions, with significantly higher reductions in risk perception for the fact list. There was also a tendency for a main effect of visualization on risk perception, indicating that visual emotionalization via positive photographs tended to lead to a greater decrease in perception of risk.

Our findings indicate that the presentation of science information is per se suitable for improving knowledge about, attitude toward, and perception of risk in human-wildlife interactions.
Against our expectations, neither textual nor visual emotionalization had an overall effect on knowledge gain or attitude, which stands in contradiction to prior research in these fields (e.g., Dirkx, 2006; Green, 2006; Ryffel et al., 2014). An explanation might be that the photographs used in the visual emotionalization condition did not transfer any additional information and thus had too little overlap with the text, which could have been detrimental to the learning process (Levin et al., 1987; Carney and Levin, 2002). It is also possible that reading narrative texts in itself elicits visual imagery in readers, so there would not be any added benefits from adding pictures to the text (Levin et al., 1987; Carney and Levin, 2002). However, our results do support the assumption that it is particularly important to achieve a suitable fit between textual and visual forms of emotionalization. Pictures intended to have an emotionalizing effect might not have been a good fit with a fact list and might probably even have had a distracting effect on information processing, which may have been the reason for less knowledge gain (Harp and Mayer, 1997; Schimmack and Derryberry, 2005). It could also be that the mere presence of emotionalizing pictures accompanying the fact list led the participants to view the fact list as a less scientific and less trustworthy information source (Flanagin and Metzger, 2008). For a narrative, however, visual emotionalization was shown to be more supportive for knowledge gain. These considerations are in line with prior research on text-picture interactions, indicating that pictures are more helpful in more complex texts (Mayer and Gallini, 1990). Moreover, the present study only tested for positive forms of emotionalization. It remains unclear whether textual or visual forms of emotionalization that induce negative emotions (e.g., drastic pictures of foxes that had died from rabies) could have a negative effect on knowledge gain or attitude formation and even increase readers' perception of risks.

With respect to changes in risk perception, textual emotionalization had a noteworthy effect: In the fact list condition, there was a greater decrease in the perception of risk than in the narrative condition. It is possible that the narrative text led to a more vivid mental representation of the risks, which has been found to lead to an increase in risk perception (Keller et al., 2006; Dunlop et al., 2008). However, there was a rather low baseline of risk perception even before our participants entered the treatment-probably because the risks are objectively low, or maybe because the participants had never heard of some of the possible infection risks. In both cases, even though the texts stated that the infection risks for several diseases were very low, the simple mentioning of these risks could have made the readers more immediately aware of them (Wahlberg and Sjoberg, 2000). It is also possible that the greater decrease in risk perception in the fact list condition occurred because participants perceived the fact list as more scientifically adequate and more trustworthy than an emotionalizing article. Thus, the information about the objectively low risks may have been cognitively better processed and remembered, resulting in the greater decrease in risk perception. We also found a tendency toward reduced risk perception through visual emotionalization. One can speculate whether this effect occurred from the sheer effect of the photographs or whether the photographs distracted readers from the risk facts in the text (Yang and Hasher, 2007). 
All in all, this study showed suitable ways for successfully improving people's knowledge about, their attitude toward, and their risk perception of foxes in urban areas. Our findings provide experimental evidence that it is generally possible to improve the public's perception and tolerance of wildlife in urban areas by using appropriate means of communication. It also made clear that the formats of visual and textual emotionalization, or their combination, should be chosen carefully, depending on the aim of the communication. Nevertheless, as some of our null hypotheses about the overall impact of textual and visual emotionalization on knowledge gain or attitude could not be rejected, open questions still remain that may be worth examining in future research.

Our findings are limited by the artificial laboratory setting, where participants were directly confronted with the text material and instructed to read it. In their everyday life, other factors, such as selection processes, effects of visual attractiveness, and the possibility to stop reading a text that is not perceived to be interesting, all can play important roles. Moreover, our sample consisted mainly of young female university students that could possibly have a more positive attitude toward wildlife conservation in general, and the sample may be not representative of the general public with regard to forming attitudes or learning abilities. One could also assume that university students are more used to acquiring factual knowledge and tend to be more skeptical toward narrative and emotionalizing content. Further study interventions should test the public's knowledge, attitudes, and risk perceptions with more diverse samples. To test effects of emotionalization on volition and persistence, future research should also include the opportunity for readers to interrupt their reading or even avoid particular information. It is also plausible that attitude formation and knowledge gain are long-term processes in everyday life, which can continue even days or weeks after reading a certain text, by thinking it over or talking about it

\section{REFERENCES}

Aron, A., and Aron, E. N. (2002). Statistics for Psychology, 3rd Ed. Englewood Cliffs, NJ: Prentice Hall.

Bateman, P. W., and Fleming, P. A. (2012). Big city life: carnivores in urban environments. J. Zool. 287, 1-23. doi:10.1111/j.1469-7998.2011.00887.x

Baumeister, R. F., Vohs, K. D., Nathan DeWall, C., and Zhang, L. (2007). How emotion shapes behavior: feedback, anticipation, and reflection, rather than direct causation. Pers. Soc. Psychol. Rev. 11, 167-203. doi:10.1177/108886830 7301033

Berkowitz, L., and Donnerstein, E. (1982). External validity is more than skin deep: some answers to criticisms of laboratory experiments. Am. Psychol. 37, 245-257. doi:10.1037/0003-066X.37.3.245

Brossard, D. (2013). New media landscapes and the science information consumer. Proc. Natl. Acad. Sci. U.S.A. 110, 14096-14101. doi:10.1073/pnas.1212744110

Brossard, D., and Scheufele, D. A. (2013). Science, new media, and the public. Science 339, 40-41. doi:10.1126/science.1232329

Bruskotter, J. T., Singh, A., Fulton, D. C., and Slagle, K. (2015). Assessing tolerance for wildlife: clarifying relations between concepts and measures. Hum. Dimens. Wildl. 20, 255-270. doi:10.1080/10871209.2015.1016387

Burns, T. W., O'Connor, D. J., and Stocklmayer, S. M. (2003). Science communication: a contemporary definition. Public Underst. Sci. 12, 183-202. doi:10.1177/09636625030122004

Carney, R. N., and Levin, J. R. (2002). Pictorial illustrations still improve students' learning from text. Educ. Psychol. Rev. 14, 5-26. doi:10.1023/A:1013176 309260 with others. In our study, the effects of dependent variables were retrieved right after the participants read the texts. Future studies should consider longer time periods between intervention and data collection and include follow-up measurements.

\section{ETHICS STATEMENT}

This study was carried out in accordance with the recommendations of the Local Ethics Committee of the Leibniz-Institut fuer Wissensmedien with written informed consent from all participants. All participants gave written informed consent in accordance with the Declaration of Helsinki. The protocol was approved by the Local Ethics Committee of the Leibniz-Institut fuer Wissensmedien (approval number: LEK 2017/001).

\section{AUTHOR CONTRIBUTIONS}

DF, UC, SK, MB, and JK made substantial contributions to the conception and design of the work; approved the final version to be published; and agreed to be accountable for all aspects of the work in ensuring that questions related to the accuracy or integrity of any part of the work are appropriately investigated and resolved. DF and JK were involved in the analysis and interpretation of data for the work; and drafted the work. UC, SK, and $\mathrm{MB}$ revised it critically for important intellectual content.

\section{FUNDING}

The research here was funded by budget resources of the LeibnizInstitut fuer Wissensmedien and the Leibniz Institute for Zoo and Wildlife Research. We also acknowledge support by Deutsche Forschungsgemeinschaft and Open Access Publishing Fund of Eberhard Karls University Tuebingen.

Cook, C. N., Mascia, M. B., Schwartz, M. W., Possingham, H. P., and Fuller, R. A. (2013). Achieving conservation science that bridges the knowledge-action boundary. Conserv. Biol. 27, 669-678. doi:10.1111/cobi.12050

Dahlstrom, M. F. (2014). Using narratives and storytelling to communicate science with nonexpert audiences. Proc. Natl. Acad. Sci. U.S.A. 111(Suppl. 4), 13614-13620. doi:10.1073/pnas.1320645111

de Bruin, W. B., and Bostrom, A. (2013). Assessing what to address in science communication. Proc. Natl. Acad. Sci. U.S.A. 110(Suppl. 3), 14062-14068. doi:10.1073/pnas.1212729110

Decker, D., Smith, C., Forstchen, A., Hare, D., Pomeranz, E., Doyle-Capitman, C., et al. (2016). Governance principles for wildlife conservation in the 21st century. Conserv. Lett. 9, 290-295. doi:10.1111/conl.12211

Dirkx, J. M. (2006). Engaging emotions in adult learning: a Jungian perspective on emotion and transformative learning. New Dir. Adult Contin. Educ. 109, 15-26. doi:10.1002/ace.204

Dunlop, S., Wakefield, M., and Kashima, Y. (2008). Can you feel it? Negative emotion, risk, and narrative in health communication. Media Psychol. 11, 52-75. doi:10.1080/15213260701853112

Dunlosky, J., Rawson, K. A., Marsh, E. J., Nathan, M. J., and Willingham, D. T. (2013). Improving students' learning with effective learning techniques: promising directions from cognitive and educational psychology. Psychol. Sci. Public Interest 14, 4-58. doi:10.1177/1529100612453266

Enck, J. W., Decker, D. J., Riley, S. J., Organ, J. F., Carpenter, L. H., and Siemer, W. F. (2006). Integrating ecological and human dimensions in adaptive management of wildlife-related impacts. Wildl. Soc. Bull. 34, 698-705. doi:10.2193/0091-764 8(2006)34[698:IEAHDI]2.0.CO;2 
Feinkohl, I., Flemming, D., Cress, U., and Kimmerle, J. (2016). The impact of epistemological beliefs and cognitive ability on recall and critical evaluation of scientific information. Cogn. Process. 17, 213-223. doi:10.1007/s10339-015-0748-Z

Fischer, C., Reperant, L. A., Weber, J. M., Hegglin, D., and Deplazes, P. (2005). Echinococcus multilocularis infections of rural, residential and urban foxes (Vulpes vulpes) in the canton of Geneva, Switzerland. Parasite 12, 339-346. doi:10.1051/parasite/2005124339

Flanagin, A. J., and Metzger, M. J. (2008). The credibility of volunteered geographic information. GeoJournal 72, 137-148. doi:10.1007/s10708-008-9188-y

Flemming, D., Cress, U., and Kimmerle, J. (2017). Processing the scientific tentativeness of medical research: an experimental study on the effects of research news and user comments in online media. Sci. Commun. 39, 745-770. doi:10.1177/1075547017738091

Flemming, D., Feinkohl, I., Cress, U., and Kimmerle, J. (2015). Individual uncertainty and the uncertainty of science: the impact of perceived conflict and general self-efficacy on the perception of tentativeness and credibility of scientific information. Front. Psychol. 6:1859. doi:10.3389/fpsyg.2015.01859

Freuling, C. M., Hampson, K., Selhorst, T., Schröder, R., Meslin, F. X., Mettenleiter, T. C., et al. (2013). The elimination of fox rabies from Europe: determinants of success and lessons for the future. Philos. Trans. R. Soc. Lond. B Biol. Sci. 368, 20120142. doi:10.1098/rstb.2012.0142

Garvey, W. D. (2014). Communication: The Essence of Science: Facilitating Information Exchange among Librarians, Scientists, Engineers and Students. Amsterdam: Elsevier.

Graesser, A. C., Hauft-Smith, K., Cohen, A. D., and Pyles, L. D. (1980). Advance outlines, familiarity, and text genre on retention of prose. J. Exp. Educ. 48, 281-290. doi:10.1080/00220973.1980.11011745

Green, M. C. (2006). Narratives and cancer communication. J. Commun. 56(Suppl. 1), S163-S183. doi:10.1111/j.1460-2466.2006.00288.x

Harp, S. F., and Mayer, R. E. (1997). The role of interest in learning from scientific text and illustrations: on the distinction between emotional interest and cognitive interest. J. Educ. Psychol. 89, 92-102. doi:10.1037/0022-0663.89.1.92

Harrison, R. L. (1998). Bobcats in residential areas: distribution and homeowner attitudes. Southwest. Nat. 43, 469-475.

Hegglin, D., Bontadina, F., Gloor, S., Romig, T., Deplazes, P., and Kern, P. (2008). Survey of public knowledge about Echinococcus multilocularis in four European countries: need for proactive information. BMC Public Health 8:247. doi:10.1186/1471-2458-8-247

Höijer, B. (2010). Emotional anchoring and objectification in the media reporting on climate change. Public Underst. Sci. 19,717-731.doi:10.1177/0963662509348863

Hudenko, H. W., Siemer, W. F., and Decker, D. J. (2010). "Urban carnivore conservation and management. The human dimension," in Urban Carnivores: Ecology, Conflict, and Conservation, eds S. D. Gehrt, S. P. D. Riley, and B. L. Cypher (Baltimore, ML: JHU Press), 79-95.

Irwin, A. (2014). "Risk, science and public communication," in Routledge Handbook of Public Communication of Science and Technology, eds M. Bucchi, and B. Trench (Abingdon, UK: Routledge), 160-172.

Jacobson, N., Butterill, D., and Goering, P. (2004). Organizational factors that influence university-based researchers' engagement in knowledge transfer activities. Sci. Commun. 25, 246-259. doi:10.1177/1075547003262038

Kansky, R., Kidd, M., and Knight, A. T. (2014). Meta-analysis of attitudes toward damage-causing mammalian wildlife. Conserv. Biol. 28, 924-938. doi:10.1111/ cobi. 12275

Keller, C., Siegrist, M., and Gutscher, H. (2006). The role of the affect and availability heuristics in risk communication. Risk Anal. 26, 631-639. doi:10.1111/j.1539-6924.2006.00773.x

Kim, J., and Morris, J. D. (2007). The power of affective response and cognitive structure in product-trial attitude formation. J. Adv. 36, 95-106. doi:10.2753/ JOA0091-3367360107

Kimmerle, J., Bientzle, M., and Cress, U. (2014). Personal experiences and emotionality in health-related knowledge exchange in Internet forums: a randomized controlled field experiment comparing responses to facts vs personal experiences. J. Med. Internet Res. 16, e277. doi:10.2196/jmir.3766

Kimmerle, J., and Cress, U. (2013). The effects of TV and film exposure on knowledge about and attitudes toward mental disorders. J. Community Psychol. 41, 931-943. doi:10.1002/jcop.21581

Kimmerle, J., Flemming, D., Feinkohl, I., and Cress, U. (2015). How laypeople understand the tentativeness of medical research news in the media: an experimental study on the perception of information about deep brain stimulation. Sci. Commun. 37, 173-189. doi:10.1177/1075547014556541
Kintsch, W. (1994). Text comprehension, memory, and learning. Am. Psychol. 49, 294-303. doi:10.1037/0003-066X.49.4.294

König, A. (2008). Fears, attitudes and opinions of suburban residents with regards to their urban foxes. Eur. J. Wildl. Res. 54, 101-109. doi:10.1007/ s10344-007-0117-z

Levin, J. R., Anglin, G. J., and Carney, R. N. (1987). "On empirically validating functions of pictures in prose," in The Psychology of Illustration: I. Basic Research, eds D. M. Willows and H. A. Houghton (New York: Springer), 51-85.

Levitt, S. D., and List, J. A. (2007). What do laboratory experiments measuring social preferences reveal about the real world? J. Econ. Perspect. 21, 153-174. doi:10.1257/jep.21.2.153

Lewis, F. I., Otero-Abad, B., Hegglin, D., Deplazes, P., and Torgerson, P. R. (2014). Dynamics of the force of infection: insights from Echinococcus multilocularis infection in foxes. PLoS Negl. Trop. Dis. 8:e2731. doi:10.1371/journal. pntd.0002731

Lundgren, R. E., and McMakin, A. H. (2013). Risk Communication: A Handbook for Communicating Environmental, Safety, and Health Risks. Hoboken, NJ: John Wiley \& Sons.

Mayer, R. E., and Gallini, J. K. (1990). When is an illustration worth ten thousand words? J. Educ. Psychol. 82, 715-726. doi:10.1037/0022-0663.82.4.715

Meijaard, E., and Sheil, D. (2007). Is wildlife research useful for wildlife conservation in the tropics? A review for Borneo with global implications. Biodivers. Conserv. 16, 3053-3065. doi:10.1007/s10531-007-9161-y

Morgan, M. G. (2002). Risk Communication: A Mental Models Approach. Cambridge, UK: Cambridge University Press.

Myers, T. A., Nisbet, M. C., Maibach, E. W., and Leiserowitz, A. A. (2012). A public health frame arouses hopeful emotions about climate change. Clim. Change 113, 1105-1112. doi:10.1007/s10584-012-0513-6

Nisbet, M. C., and Scheufele, D. A. (2009). What's next for science communication? Promising directions and lingering distractions. Am. J. Bot. 96, 1767-1778. doi:10.3732/ajb.0900041

Nummenmaa, L., Hyönä, J., and Calvo, M. G. (2006). Eye movement assessment of selective attentional capture by emotional pictures. Emotion 6, 257-268. doi:10.1037/1528-3542.6.2.257

Petty, R. E., DeSteno, D., and Rucker, D. D. (2001). "The role of affect in attitude change," in Handbook of Affect and Social Cognition, ed. J. P. Forgas (Mahwah, NJ: Erlbaum), 212-233.

Ryffel, F. A., Wirz, D. S., Kühne, R., and Wirth, W. (2014). How emotional media reports influence attitude formation and change: the interplay of attitude base, attitude certainty, and persuasion. Media Psychol. 17, 397-419. doi:10.1080/15 213269.2014.933850

Sáenz, L. M., and Fuchs, L. S. (2002). Examining the reading difficulty of secondary students with learning disabilities: expository versus narrative text. Remedial Spec. Educ. 23, 31-41. doi:10.1177/074193250202300105

Š́álek, M., Drahníková, L., and Tkadlec, E. (2015). Changes in home range sizes and population densities of carnivore species along the natural to urban habitat gradient. Mamm. Rev. 45, 1-14. doi:10.1111/mam.12027

Sapp, S. G., Korsching, P. F., Arnot, C., and Wilson, J. J. (2013). Science communication and the rationality of public opinion formation. Sci. Commun. 35, 734-757. doi:10.1177/1075547013480491

Saunders, C. D., Brook, A. T., and Myers, O. E. (2006). Using psychology to save biodiversity and human well-being. Conserv. Biol. 20, 702-705. doi:10.1111/j.1523-1739.2006.00435.x

Schimmack, U., and Derryberry, D. (2005). Attentional interference effects of emotional pictures: threat, negativity, or arousal? Emotion 5, 55-66. doi:10.1037/1528-3542.5.1.55

Sinatra, G. M., Kienhues, D., and Hofer, B. K. (2014). Addressing challenges to public understanding of science: epistemic cognition, motivated reasoning, and conceptual change. Educ. Psychol. 49, 123-138. doi:10.1080/00461520.20 14.916216

Slovic, P., and Peters, E. (2006). Risk perception and affect. Curr. Dir. Psychol. Sci. 15, 322-325. doi:10.1111/j.1467-8721.2006.00461.x

Soto-Shoender, J. R., and Main, M. B. (2013). Differences in stakeholder perceptions of the jaguar Panthera onca and puma Puma concolor in the tropical lowlands of Guatemala. Oryx 47, 109-112. doi:10.1017/S0030605313000318

Thornton, C., and Quinn, M. S. (2009). Coexisting with cougars: public perceptions, attitudes, and awareness of cougars on the urban-rural fringe of Calgary, Alberta, Canada. Hum. Wildl. Confl. 3, 282-295.

Turner, M. M. (2007). Using emotion in risk communication: the anger activism model. Public Relations Rev. 33, 114-119. doi:10.1016/j.pubrev.2006.11.013 
Wahlberg, A. A., and Sjoberg, L. (2000). Risk perception and the media. J. Risk Res 3, 31-50. doi:10.1080/136698700376699

Webb, S. (2008). The effects of context on incidental vocabulary learning. Read. Foreign Lang. 20, 232-245.

Williams, C. K., Ericsson, G., and Heberlein, T. A. (2002). A quantitative summary of attitudes toward wolves and their reintroduction (1972-2000). Wildl. Soc. Bull. 30, 575-584.

Yang, L., and Hasher, L. (2007). The enhanced effects of pictorial distraction in older adults. J. Gerontol. B Psychol. Sci. Soc. Sci. 62, 230-233. doi:10.1093/ geronb/62.4.P230
Conflict of Interest Statement: The authors declare that the research was conducted in the absence of any commercial or financial relationships that could be construed as a potential conflict of interest.

Copyright (๑) 2018 Flemming, Cress, Kimmig, Brandt and Kimmerle. This is an openaccess article distributed under the terms of the Creative Commons Attribution License (CC BY). The use, distribution or reproduction in other forums is permitted, provided the original author(s) and the copyright owner are credited and that the original publication in this journal is cited, in accordance with accepted academic practice. No use, distribution or reproduction is permitted which does not comply with these terms. 